\title{
Soil erosion vulnerability and adaptation strategies in maize field of Sindhukhola sub-watershed region, Nepal
}

\author{
Bibek Panta ${ }^{1} \cdot$ Thaneshwar Bhandari ${ }^{2} \cdot$ Basanta Paudel $^{3}$
}

Received: 24 July 2020 / Accepted: 20 October 2020 / Published online: 3 November 2020

(c) Springer Nature Switzerland AG 2020

\begin{abstract}
Erosion is a major concern of hill maize farming system. Watersheds with steep slope and fragile land are more prone to erosion. A perception based semi structured questionnaire survey was carried out in Thakani and Sindhukot of Melamchi municipality in Sindhupalchowk district to study relationships of erosion in maize field along with assessment of vulnerability and factors affecting adoption of prevention measures. Index ranking method and descriptive statistics were used to rank the perception of farmers pertaining to occurrence, causes and available control measures of erosion. Logit regression further assessed the determinants of adoption of erosion prevention measures where as vulnerability was assessed using integrated vulnerability assessment approach following Intergovernmental Panel on Climate Change (IPCC) guideline. Most of the surveyed farmers responded heavy rainfall as major cause of the erosion followed by weak geography whereas the intensity of erosion was moderately increasing. Majority of the respondents (72.5\%) have not adopted any erosion prevention measures mainly due to no support from government and low income. Among various adaptation measures, most of the farmers have shifted cultivation time, improved drainage system and decreased weeding frequency. The logit regression showed that among the independent variables, income, education, gender, access to extension services and involvement in organizations are positively significant to the adoption decision. This implies farmers in prone area need support from government to adopt prevention measures. Low income household dependent on agriculture and marginal farmers were more vulnerable to erosion as they have low adaptive capacity and resilience power.
\end{abstract}

Keywords Adaptation strategies $\cdot$ Income $\cdot$ Index $\cdot$ Logit $\cdot$ Vulnerability

\section{Introduction}

Nepal is ranked very high in terms of vulnerability to natural calamities [1]; fourth most vulnerable country to climate change, eleventh vulnerable to earthquake and thirtieth vulnerable to flood and erosion [2]. A heavy reliance on agriculture makes Nepal economy more vulnerable to climatic disaster [3]. Among the major hazards, floods, erosion and landslides are the most recurrent in Nepal, claiming on an average of about 211 lives annually in the past
10 years [3]. Soil erosion is major issue of mountainous ecosystem [4], and the soil loss from landslides is most significant form of erosion in steep hill landscapes $[5,6]$. The country's climatic scenario is noted as increase in temperature and decrease in frequency of rainfall over last 15 years between 2000 and 2015, but the short-term heavy rainfall is more frequent than previous decade [7], which favors more erosion in mid hills and mountain regions of Nepal. Erosion is prominent in sloping terraces under rain-fed agriculture in middle mountain regions of Nepal [8]. In

$\triangle$ Bibek Panta, bibekpanta7@gmail.com | 'Ministry of Land Management, Agriculture and Cooperative, Butwal, Lumbini Province, Nepal. ${ }^{2}$ Department of Agricultural Economics, Postgraduate Program, Institute of Agriculture and Animal Science, Tribhuvan University, Kritipur, Nepal. ${ }^{3}$ Key Laboratory of Land Surface Pattern and Simulation, Institute of Geographic Sciences and Natural Resources Research (IGSNRR), Chinese Academy of Sciences (CAS), Beijing, China. 
the mid-hills, soil is of medium to light texture with a predominance of coarse-grained sand and gravel [9], which is more prone to erosion. Conventional tillage practice in fragile land of high and mid-hills of Nepal accelerates the erosion in rainy season [10]. Agricultural intensification has also caused soil degradation through erosion and nutrition depletion [11]. Morgan et al. [12] has reported annual soil loss rates are the highest (up to 56 tons/ha/year) in the areas with rain-fed cultivation, which is directly related to the sloping nature of the terraces.

Maize is the most cultivated crop grown in Sindhupalchowk district covering 23,650 ha cultivable land [13] mostly in upland. Soil erosion is one of the major abiotic constraints faced by maize grower in the mid hills [14] and high hills where maize is grown under rain fed condition. $40.65 \%$ area of Sindhupalchowk is highly hazardous and $52.65 \%$ area is moderately hazard prone to erosion [15]. Soil erosion and loss of cultivable soil is major problem in arable land of Sindhukhola sub-watershed region of which $66.25 \%$ of land is cultivated [16]. Movement of earth, rock or debris down slope under the influence of gravity by certain processes like rain and the wind is considered as erosion. Conventional tillage practice coupled with intermittent but intensive rainfall has degraded soil via erosion. Runoff due to precipitation erode soil mostly through rill erosion and sometime through sheet erosion. The economic losses caused by small-scale landslides are no less than any other big event of natural disaster [17].

Cutter et al. [18] defines vulnerability as the susceptibility of a given population, system, or place to harm from exposure to the hazard and directly affects the ability to prepare for, respond to, and recover from hazards and disasters. Vulnerability assessment is crucial in disaster management [19]. Vulnerability encompasses three interacting components: exposure, sensitivity and adaptive capacity. Vulnerability is highly differentiated and influenced by a range of social, economic and physical indicators. Social characteristic is more determining factor of vulnerability as shown by the most of the past studies [20]. Social vulnerability and low adaptive capacity cause social and demographic challenges [21]. Adaptation is one of the policy options for reducing the negative impacts of climate change on agriculture $[22,23]$. To reduce the vulnerability of erosion, prime need is identifying more coping strategies of erosion.

Assessing the impact of erosion is essentially important part to plan coping strategies of emerging uncertainties. Knowledge on vulnerable group and existing adaptation measures will help policy makers to formulate effective plan. Sufficient study has not been made to explore measures for coping with erosion in maize field of Sindhukhola sub-watershed region. The aim of this study is to assess the determinants of adoption of erosion control measures and to explore the vulnerable group of the erosion. This study also investigates effect of erosion in maize production and adaptation activities carried out by the farmers. The findings of the study will contribute toward existing knowledge gap, and help researchers, farmers and policy makers to respond to erosion by adjusting different policies and practices related to adaptation strategies.

\section{Materials and methods}

\subsection{Study area}

Sindhukhola is one of the tributaries of Indrawati River situated in Sindhupalchowk district of Nepal. It is subwatershed of Indrawati River which runs North-West to South-East and is located in the center of the catchment. Geographically Sindhukhola sub-watershed expands from $27^{\circ} 51^{\prime}$ to $27^{\circ} 46.30^{\prime}$ north latitude and $85^{\circ} 27^{\prime}$ to $85^{\circ} 34^{\prime}$ east longitude. It lies around $1600 \mathrm{MASL}$. Average annual rainfall is about $1615 \mathrm{~mm}$ and average mean temperature is $20.8{ }^{\circ} \mathrm{C}$ [24]. Climatically the region lies in temperate climate with dry winter and hot summer [25]. This subwatershed region occupies $49.8 \mathrm{~km}^{2}$ of area (Fig. 1). Catchment area of Sindhukhola sub-watershed region expands through parts of Bansbari, Thakani, Sindhukot, Haibung and Bhotechaur of Sindhupalchowk district. Most of the area of sub-watershed region is covered by forest, $51.73 \%$ followed by arable land, 46.88\% in 2010 [26] (Table 1, Fig. 2). Sindhukhola sub-watershed was selected purposively as the region is prone to the erosion. Study was carried on Thakani and Sindhukot of Melamchi municipality as occurrence of erosion is more.

\subsection{Data and data collection technique}

Study used both the primary and secondary data sources. The primary data were collected through household survey of Thakani (ward number 4) and Sindhukot (ward number 5) of Melamchi municipality. As per the record of local administration, there were altogether 1205 households in both wards. Sampling frame was prepared with the help of local leaders and key government personnel by categorizing respondents into severely affected, moderately affected and unaffected households. Then, study selected 120 respondents (9.95\% households) from the sampling frame by using simple random sampling technique. These data were supplemented and verified by the data collected through Informal Group Discussion (IGD). Semi-structured checklists were used for informal group discussion whereas interview schedule was prepared for interviewing respondents in household survey. Both open and close end type questions were included in interview 


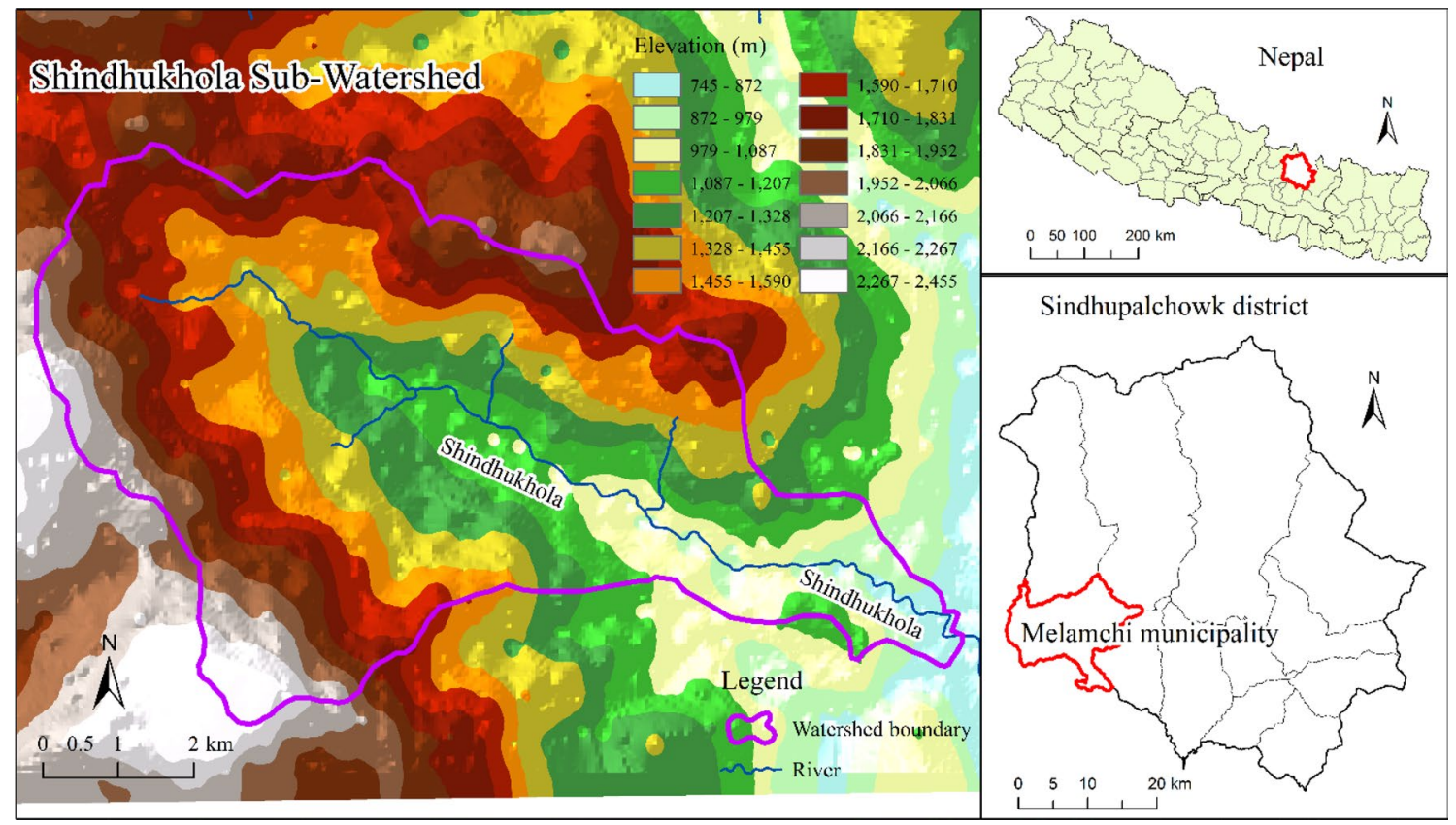

Fig. 1 The altitudinal and administrative details of the study area

Table 1 Land use and land cover status of Sindhukhola sub-watershed region

\begin{tabular}{lll}
\hline Land use type & Area $\left(\mathrm{km}^{2}\right)$ & Percent (\%) \\
\hline Agricultural land & 23.351 & 46.88 \\
Forest & 25.771 & 51.73 \\
Grassland & 0.671 & 1.35 \\
Barren area & 0.015 & 0.03 \\
Water body & 0.006 & 0.01 \\
Total area & 49.814 & 100.00 \\
\hline
\end{tabular}

Data source [26]

schedule. Furthermore, secondary data were collected through various publications and records of District Development Committee, District Agriculture Development Office, District Election Commission and local nongovernmental organizations.

\subsection{Method and technique of data analysis}

The collected data were processed and tabulated. Various descriptive and inferential statistics were used for analysis. To describe the socioeconomic characteristics descriptive statistics like mean, standard deviation, range, percentage and frequencies were used. Logistic Regression Model was used to assess the determinants of farmers' decision to practice different adaptation strategies and Indexing method to rank the preference of respondents on various issues. The analysis was done with the help of SPSS, STATA, Excel and Word software packages.

\subsection{Specification of model}

\subsubsection{Conceptual framework of logistic regression model}

Logit regression model was used to study the factors determining adoption of erosion control measures in maize field. In the logit model, suppose $Y_{1}$ be the binary response of the farmers and take only two possible values; $Y=1$, if farmers practiced different adaptation strategies and $Y=0$, if farmers do not adopt any adaptation strategies. Suppose $X$ was the vector of several explanatory variables affecting to practice different strategies and $\beta$, a vector of slope parameters, which measures the changes in $X$ on the probability of the farmers to practice adaptation strategies. The probability of binary response was defined in Eq. (1) as follows:

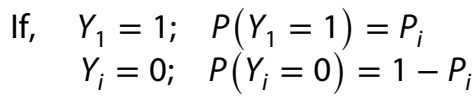

where, $P_{i}=E(Y=1 / x)$ represents the conditional mean of $Y$ given certain values of $X$.

The logit transformation of the probability of the practicing adaptation strategies by farmers was represented (Eq. 2) as follows [27]. 


\section{Landuse and land cover}

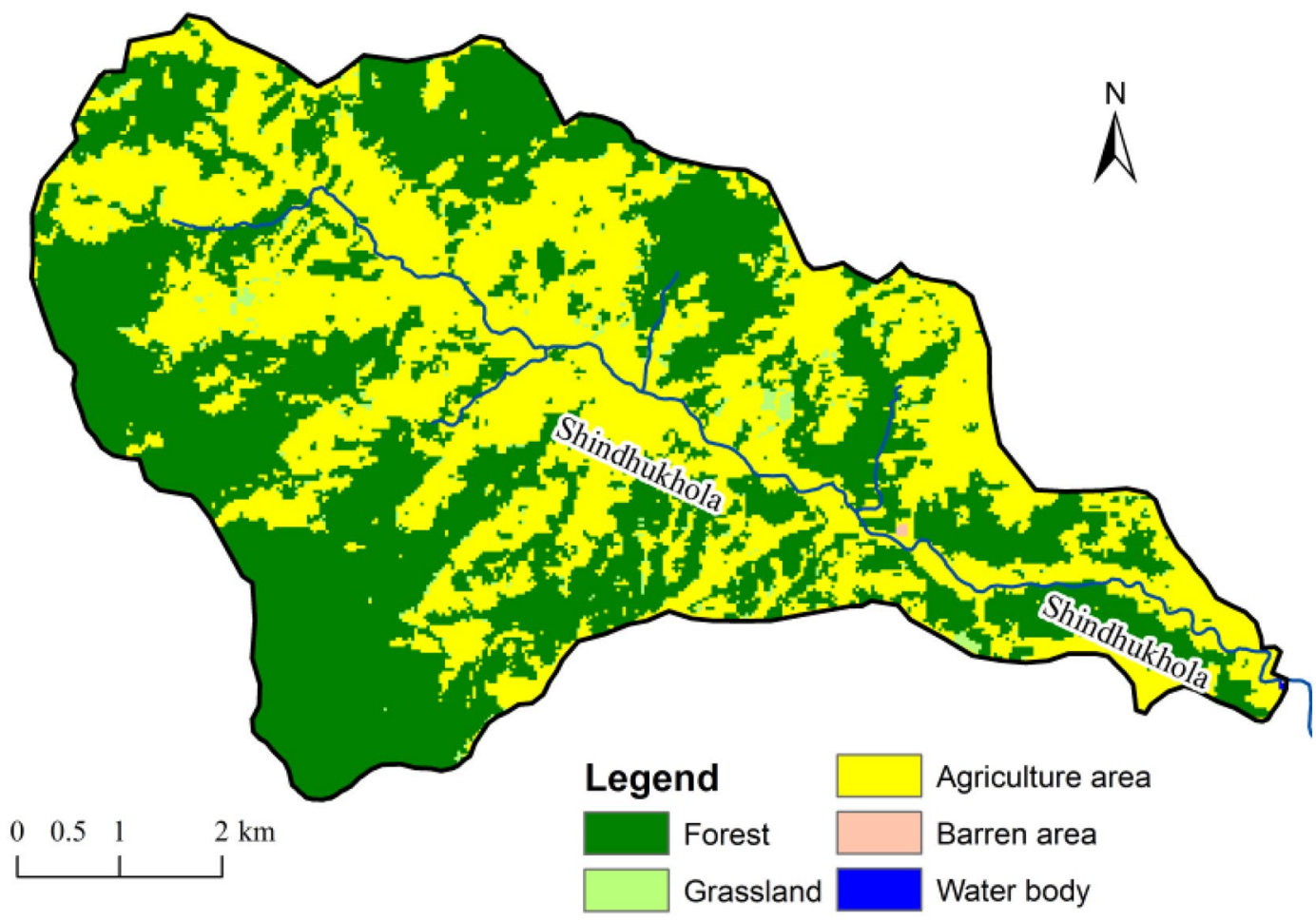

Fig. 2 Land use and land cover of Sindhukhola sub-watershed. Data source [26]

$L_{i}=\ln \left[P_{i} / 1-P_{i}\right]=z_{i}=\alpha+\sum_{i=1^{n}} \beta_{i} x_{i}+\mathrm{E}_{1}$

where $Y_{i}=$ a binary dependent variable $(1$, if farmers practicing adaptation strategies, 0 otherwise), $x_{i}$ includes the vectors of explanatory variables used in the model, $\beta_{i}=$ parameters to be estimated, $E=$ error term of the model, $\exp (\mathrm{e})=$ base of the natural logarithms, $L_{i}=$ Logit and $\left[P_{i} / 1-P_{i}\right]=$ odd ratios. Thus, the binary logit regression model was expressed as: $Y_{i}=f\left(\beta_{i} x_{i}\right)=f$ (education, land holding, income, age, gender, number of economically active member, family size, member of organization and access to extension).

\subsubsection{Description of explanatory variables}

The dependent variable is adoption of prevention measure of erosion. Various independent variables were used which are described in Table 2. Formal education of household head was assumed to be positive with adoption of prevention measures, because educated individual likely to have knowledge on prevention measures and can assess the possible social and economic damage of erosion in absence of prevention measure. Total land holdings of household also assumed to have positive relationship with adoption of prevention measures as more land holdings can cause more loss from erosion, thus household will be compel to adopt prevention measures. All the prevention measures require expenses thus households with higher income and more economically active members in family are assumed to have positive relationship with adoption of prevention measures. Older people are expected to deny the adoption measure as they are less interested to adopt prevention measures thus age is assumed to have negative relationship with adoption decision. Among all the business established in the country, $70.3 \%$ of the business are owned by male [28] which shows men in Nepalese society have control over resources and enjoy more income opportunities than women. Men may also have better knowledge on control measures because of higher mobility in the society. It was, therefore, assumed that males would express greater prefer for adoption of prevention measures compared to female. Less the family size, more will be saving and more preference will be for prevention measures thus family size is assumed to have negative relationship with adoption of prevention measures. Both access to extension services and membership of organizations help to develop knowledge about possible

\section{SN Applied Sciences}


Table 2 Descriptions of the variables used in the logit model

\begin{tabular}{|c|c|c|c|}
\hline Variables & Descriptions & Value & $\begin{array}{l}\text { Expected } \\
\text { relation- } \\
\text { ship }\end{array}$ \\
\hline Education (year) & Number of years of education of household head & Year & + \\
\hline Land (hectare) & Land holdings of household & ha & + \\
\hline Total income (NRS) & Total household income & Rupees & + \\
\hline Age (years) & Age of the household head & Years & - \\
\hline Gender & Gender of the household head & 1 if male, 0 otherwise & + \\
\hline Economically active member & $\begin{array}{l}\text { Number of economically active (16-59 years) family members in the } \\
\text { household }\end{array}$ & Number & + \\
\hline Family size (numbers) & Number of family members in the household & Number & - \\
\hline Member of organization & Whether the farmers have membership in any organization or not & 1 if yes, 0 otherwise & + \\
\hline Access to extension service & Whether the household have access to extension service or not & 1 if yes, 0 otherwise & + \\
\hline
\end{tabular}

Note: + indicates positive relationship and - indicates negative relationship of dependent variable with independent variable

damage of erosion and control measures, thus expected to have positive relationship with adoption decision.

\subsubsection{Indexing method}

Various problems and reasons were ranked with the use of index. Scaling techniques, which provides the direction and extremity attitude of the respondent toward any proposition [29] was used to construct index. The intensity of disaster faced by the farmers and reasons for not adopting disaster mitigation methods were identified by using five point scaling technique comparing strongly agree, fairly agree, neutral, fairly disagree and strongly disagree using scores of $1.0,0.8,0.6 .0 .4$ and 0.2 , respectively. The formula given below was used to find the index for intensity of various problems/reasons.

$I=\Sigma$ coefficient $*$ frequency $/ N$

where

$I=$ Index value for intensity of problem or ranking best solution

$\Sigma=$ Summation

$N=$ Sample size

\subsection{Vulnerability assessment}

Vulnerability was measured by using integrated vulnerability assessment approach following the IPCC [30] guideline. This approach uses both the external biophysical dimension and the internal social dimension of a system [31]. External biophysical dimension measures exposure whereas social dimension measures adaptive capacity and sensitivity. Vulnerability index has been used to assess the relative vulnerability [32]. It is because the set of indicators have different units and scales, methodology adopted by Vincent [33] was used to standardize the variables to have a mean of 0 and a standard deviation of 1 using Eq. (3):

$Z_{i j}=\frac{x_{i j}-\bar{x}}{s_{X}}$

where $Z_{i j}$ is the standardized value, $x_{i j}$ is the $j$ th indicator value for the $i$ th household, $\bar{x}$ the arithmetic mean of the given indicator across different households, and $s_{x}$ the standard deviation. Standardization of individual variables provides a linear transformation which allows for the summation of variables with different scales [34]. After standardization, we assign a weight to each indicator using principal component analysis (PCA). The use of PCA avoids the chances of unequal weighting while using diverse indicators [35]. The standardized value is multiplied with the component 1 score obtained from the PCA to get the respective index value. Similar procedure was used by Pathak et al. [36] on study of flood vulnerability in Saptari district of Nepal. A higher value of vulnerability index indicates lower vulnerability and vice versa. However the index number does not represent exact vulnerability rather it is comparative indicator.

Following the definition provided by the IPCC [30], vulnerability is calculated as the net effect of adaptive capacity, exposure, and sensitivity (Eq. 4) using variables (Table 3):

Vulnerability $=$ Adaptive Capacity - Sensitivity - Exposure

$\mathrm{EVI}_{i}=\sum_{j=1}^{10} x_{i j} w_{x j}-\sum_{j=1}^{5} y_{i j} w_{y j}-\sum_{j=1}^{4} z_{i j} w_{z j}$

where $\mathrm{EVI}_{i}=$ erosion vulnerability index of $i$ th household, $x=$ adaptive capacity variables, $y=$ sensitivity variables, 
Table 3 Variables used to calculate vulnerability index and their functional relationship

\begin{tabular}{lll}
\hline & Indicator & $\begin{array}{c}\text { Func- } \\
\text { tional } \\
\text { relation }\end{array}$ \\
\hline Adaptive capacity & Age of Household head & - \\
Gender of Household head $(1=$ male, $0=$ otherwise $)$ & + \\
Family size & - \\
Years of schooling of Household head & - \\
House type $(1=$ concrete, $0=$ otherwise $)$ & - \\
Household income & - \\
Access to credit facility $(1=$ yes, $0=$ otherwise $)$ & - \\
Use of erosion control measures $(1=$ yes, $0=$ otherwise $)$ & - \\
Access to extension (1=yes, $0=$ otherwise $)$ & + \\
Involvement in institution $(1=$ yes, $0=$ otherwise $)$ & + \\
Proportion of female members & + \\
Dependency ratio & + \\
Proportion of agricultural income to total income & + \\
Proportion of dependent population to total population & + \\
Proportion of illiterate population & + \\
Perception of erosion frequency $(1=$ increasing, $0=$ otherwise $)$ & + \\
Perception of erosion intensity $(1=$ high, $0=$ otherwise $)$ & + \\
Perception of rainfall intensity $(1=$ high, $0=$ otherwise $)$ & + \\
Proportion of arable land to total land & + \\
\hline
\end{tabular}

$z=$ exposure variables, and $w=$ weights obtained from principal component analysis for jth indicator.

\section{Results and discussion}

\subsection{Socioeconomic characteristics}

The total population of 120 sampled household was found to be 654 , out of which $74.2 \%$ were male and $25.8 \%$ were female. In both wads male population were more than female populations. The surveyed households were dominated by the Brahmin community in both of the wads; Thakani and Sindhukot which accounts about 38.3\%. Indigenous and Dalits were almost comparable among respondents. The total populations of the sampled households were categorized into three age groups. Among them the economically active population referred to the respondents belonging to the age group of 15-59 years. Around $57.12 \%$ of respondents were economically active. The literacy rate of surveyed household head was $84.27 \%$ which was higher than district average of $71.1 \%$. Largest proportion of the household head in surveyed households attained primary level education and lowest proportion recorded higher level education. Agriculture is the dominant occupation of the household members surveyed which accounts $78.93 \%$ which is more than peoples involved in agriculture in the country (65.6\%). Service is the second source of income (11.93\%) among respondent family members followed by Remittance $(5.08 \%)$ and business (4.06\%) (Table 4$)$.

\subsection{Agricultural characteristics}

Cropping pattern of a location is influenced by climatic condition, socioeconomic condition and infrastructure

Table 4 Socioeconomic characters of sample and population of study area

\begin{tabular}{lll}
\hline Socioeconomic characters & Sample & Population \\
\hline Gender & & \\
(a) Male & 319 & 3053 \\
(b) Female & 336 & 3511 \\
(c) Total population & 654 & 6564 \\
Ethnicity & & \\
(a) Brahmin/Chettri (privilege community) & 376 & 1919 \\
(b) Indigenous & 142 & 3725 \\
(c) Dalit (marginal community) & 136 & 900 \\
Economically active population & 365 & 3546 \\
Literacy rate & $65.20 \%$ & $59.50 \%$ \\
Occupation & & \\
(a) Agriculture & $48.67 \%$ & $65.60 \%$ \\
(b) Others & $51.33 \%$ & $34.40 \%$ \\
\hline
\end{tabular}

Source: Household survey 2017 and CBS, 2018 [13] 
development. Maize is major crop of the farming system in mid hills. Maize intercropped with millet was followed by mustard whereas in somewhere followed by wheat. Cropping pattern including three crops consist Maize-MilletPotato. In the study area, cauliflower and cabbage were major winter vegetable crops but cowpea obtained more emphasis on commercial cultivation since last 10 years. Majority of the households in the study area belonged to the small land holding category. About $75 \%$ of the household population had land holding below 0.5 ha followed by medium holding (0.5-1 ha). Least household (0.8\%) possessed large holding in the sampled household. The average holding was below average holding of the districts. Wildlife damage was major constraint prevailed in maize cultivation area as the site being buffer zone of Shivapuri conservation area. Erosion, drought, insect/pest incidence were other the major disasters prevailed in the area.

\subsection{Soil erosion in maize field}

\subsubsection{Perception of farmer on occurrence of erosion}

Respondents were asked their response about the intensity of erosion in past few years. Their response was categorized into four groups, viz. severely increasing, moderately increasing, neutral and slowly decreasing. Most of the farmers $(41.7 \%)$ responded the intensity of erosion was moderately increasing in the past few years where as $32.5 \%$ of respondents responded erosion was severely increasing (Table 5). Several studies have also reported erosion rate is increasing at decreasing rate in hills of Nepal. In the study performed by Chalise and Kumar [37], soil erosion rate has increased from 5.35 t/ha/year in 1995 to $6.03 \mathrm{t} / \mathrm{ha}$ /year in 2015 which shows erosion is increasing but at slower rate. The estimated annual erosion was 129.30 million tons in 1990 and 110.53 million tons in 2010 [38]. Fewest of the respondents, only $5 \%$ felt the intensity of erosion was decreasing in past few years. Rill erosion is the most common type of erosion occurred in maize field followed by sheet erosion.

Table 5 Perception of farmers on erosion occurrence

\begin{tabular}{lll}
\hline Response & Frequency & Percent \\
\hline Severely increasing & 39 & 32.5 \\
Moderately increasing & 50 & 41.7 \\
Neutral & 25 & 20.8 \\
Slowly decreasing & 6 & 5 \\
Total & 120 & 100 \\
\hline
\end{tabular}

Source: Household survey 2017

\subsubsection{Causes of soil erosion}

Causes of erosion were categorized into five groups, viz. heavy rainfall, weaker geography, deforestation, drought and wind. By using indexing method, prioritization of causes of erosion was studied. Most of the respondents ranked heavy rainfall as major causes of erosion (Table 6). Erosion increases with precipitation in watershed [39]. Rainfall erosivity during monsoon season is higher compared with other seasons (i.e., $85 \%$ ) followed by pre-monsoon (3.5\%) and post-monsoon (2.8\%) [40]. The weak geographical structure was ranked as second causes for the erosion. In most of the study area, geographic structure is such even small rainfall causes the havoc of erosion. In few cases wind and drought has also caused the erosion. Shen et al. [41] has also figured out rainfall intensity and land topography as major cause of the erosion in hill slopes. Along with rainfall, poor land management also leads to soil loss from agriculture land [42].

The rainfall pattern of study area since past 54 years shows that total rainfall amount is decreasing year by year in past few years (Fig. 3). As rainfall is major cause of erosion, the perception of farmers' about erosion that in past few years moderately increasing is in par with rainfall pattern.

Table 6 Causes of erosion in the study area

\begin{tabular}{lll}
\hline Causes & Index value & Rank \\
\hline Heavy rainfall & 0.91 & I \\
Weaker geography & 0.64 & II \\
Deforestation & 0.61 & III \\
Drought & 0.55 & IV \\
Wind & 0.29 & V \\
\hline
\end{tabular}

Source: Household survey 2017

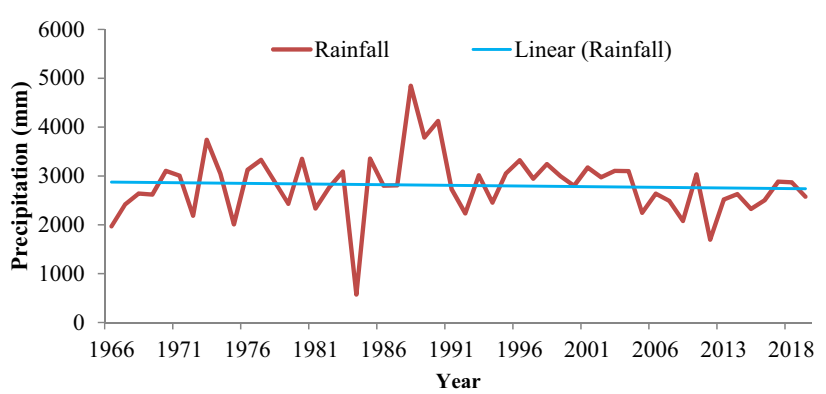

Fig. 3 Trend analysis of rainfall. Source of data: Department of Hydrology and Meteorology 


\subsubsection{Perception of farmers on effect of soil erosion in maize production}

Respondents were also asked their response on the impact of erosion in the yield of maize crop. Responses were categorized into three groups, viz. high impact, low impact and no impact. Most of the farmers i.e., $60 \%$ of the respondents felt there is less impact of the erosion in the yield of maize where as $35 \%$ of the farmers responded there is high loss in yield of maize crop due to erosion. Only $5 \%$ of the respondent farmers felt there is no loss in the yield of maize crop due to erosion. Data on annual maize production and productivity also suggest there is no significant decline in maize yield due to erosion in course of time.

\subsection{Adaptors and adaptation measures in study area}

Adaptation is an iterative, dynamic, multi scale, and multiactor process, not a mechanical adjustment to a current state [43]. Most of the farmers i.e., $72.5 \%$ of the farmers are non-adaptors of the mitigation methods and only $27.5 \%$ are adopters of the mitigation measure. Farmers in the study area practiced different adaptation strategies to cope with erosion in maize field. In order to escape the problem of erosion in maize field, most of the farmers have shifted the cultivation time. Earlier they use to sow the maize before pre-monsoon but now they delayed the planting. Likewise they improved drainage system, decreased weeding frequencies, changed variety, practice minimum tillage, mulching, inter cropping and terrace cultivation. On a study performed by Das and Bauer [44], intercropping and minimum tillage were significant in reducing erosion. Conservation agriculture system is effective for increasing return and improving sustainability of the farming system in maize based farming system of Nepal [45]. Mulching has shown better result to control erosion on several studies [46-48] in maize based cropping system of mid-hills.

\subsection{Reasons for no adoption}

Most of the respondents blamed inadequate government support as the major cause for no adoption (Table 7). Most of the mitigation methods require extra expenses and resources. Farmers could not afford the extra expenses so they are not able to adopt the mitigation measures. Brouwer et al. [49] also figured out insufficient financial means as a major cause of no adoption of prevention measures by residents in prone area. Likewise, due to low income, lack of credit facility and poor access to technology, some
Table 7 Reasons for no adoption of mitigation methods

\begin{tabular}{lll}
\hline Barriers to adaptation & Index value & Rank \\
\hline No support from government & 0.96 & I \\
High cost and low income & 0.95 & II \\
No credit facility & 0.83 & III \\
Poor access to technology & 0.69 & IV \\
Lack of knowledge \&information & 0.66 & V \\
Labor unavailability & 0.57 & VI \\
No early warning system & 0.35 & VII \\
\hline
\end{tabular}

Source: Household survey 2017

of the farmers were not able to adopt the mitigation measures (Table 7). Ishaya and Abaje [50] also reported several above-mentioned factors as constraint for adoption.

\subsection{Determinants of adoption of erosion control measure}

Socio-demographic factors (age, gender, education, family size, economically active members in family, land area, total income) and institutional factors (access to extension, member of organizations) were used as independent variables in model. The overall model is significant at $1 \%$ level of significance with $\chi^{2}$ value 51 and correct prediction value is $84.8 \%$ (Table 8 ), indicating the model fit is good (model with explanatory). The Pseudo $R^{2}$ value (Nagelkerke $R^{2}$ ) of the model was 0.520 indicating strong association of dependent variables with independent variables. The Wald value of statistical analysis also suggests independent variables have strong influence on dependent variable.

The result from logit regression analysis showed five variables were statistically significant for practicing adaptation strategies, they were; income, gender of household head, education of household head, access to extension service and involvement in any organization or group. Four other variables, namely age, family size, economically active people and total land were statistically insignificant.

Education level of the household was positively significant at $1 \%$ level of significance to use control measures of soil erosion. As per the value of odd ratio, keeping other factors constant, a unit increase in year of education of $\mathrm{HH}$ head will increase probability of adoption of control measures by $69 \%$. Higher level of education may increase the ability of farmers to make innovative decision pertaining to erosion control measures. Several studies have reported increase in years of schooling results increase in the probability of adoption of prevention measures to disaster $[35,51]$. Higher level of education is often hypothesized to increase the probability of adopting new technologies [52]. 
Table 8 Logit regression result of identifying determinants of adaptation strategies to the erosion

\begin{tabular}{|c|c|c|c|c|c|}
\hline & $B$ & S.E. & Wald & Sig. & $\operatorname{Exp}(B)$ \\
\hline Age (years) & -0.025 & 0.027 & 0.907 & 0.341 & 0.975 \\
\hline Gender (\#) & 1.250 & 0.646 & 3.742 & $0.053^{*}$ & 3.491 \\
\hline Education & -0.369 & 0.123 & 9.052 & $0.003^{* * *}$ & 0.692 \\
\hline Family size & 0.319 & 0.213 & 2.236 & 0.135 & 1.375 \\
\hline Economically active & -0.457 & 0.272 & 2.827 & 0.093 & 0.633 \\
\hline Land (ha) & 0.099 & 0.082 & 1.480 & 0.224 & 1.104 \\
\hline Total income (NRS) & 0.000 & 0.000 & 6.858 & $0.009^{* * *}$ & 1.000 \\
\hline $\begin{array}{l}\text { Member of organization } \\
\text { (\#) }\end{array}$ & 2.035 & 0.898 & 5.140 & $0.023^{* *}$ & 7.651 \\
\hline Access to extension (\#) & 1.827 & 1.067 & 2.933 & $0.087^{*}$ & 6.216 \\
\hline Constant & -2.679 & 3.025 & 0.785 & 0.376 & 0.069 \\
\hline Summary statistics & & & & & \\
\hline No. of observation $(N)$ & \multicolumn{5}{|l|}{120} \\
\hline Log likelihood & \multicolumn{5}{|l|}{-84.851} \\
\hline $\begin{array}{l}\text { Model chi-square value } \\
\text { (Omnibus test of model } \\
\text { coefficient) }\end{array}$ & \multicolumn{5}{|c|}{$50.951^{* * *}\left(\right.$ Prob $\left.>\chi^{2}=0.000\right)$} \\
\hline $\begin{array}{l}\text { Pseudo } R^{2} \text { value (Nagel- } \\
\text { kerke } R^{2} \text { ) }\end{array}$ & \multicolumn{5}{|l|}{0.520} \\
\hline Overall correct prediction & \multicolumn{5}{|l|}{$84.8 \%$} \\
\hline
\end{tabular}

(\#) represents dummy variable

*Significant at $p=0.01$; ${ }^{* *}$ Significant at $p=0.05 ;{ }^{* *}$ Significant at $p=0.1$; Rest of other are nonsignificant at $p \geq 0.1$

Income of the family was positively significant to adoption of erosion control strategies at $1 \%$ level of significance. Result shows that a unit increase in income of family increases probability of adoption of control measures by a unit, i.e., $100 \%$ keeping other factors constant. This is in par with the findings of Okoye [53] and Nadhomi et al. [54] where they suggested income of farmers influences the adoption of recommended practices. The reason may be that use of control measure requires certain amount of money, so higher income family would adopt the measure. Mostly financially well-off household is innovative in decision making.

Involvement of $\mathrm{HH}$ in organizations like groups or cooperatives (dummy variable) was also significant to adoption of control measures at 5\% level of significance. Involvement in social groups or organizations will allow farmers to share their experiences and knowledge among them. This will convince farmers regarding adoption of control measures and spread of information is also quicker through group approach. On a study by Tiwari et al. [55] showed that technology dissemination through multi-sectoral type community based local groups is a good option to enhance the adoption of improved soil conservation technology in the Middle Mountain farming systems in Nepal. Jianjun et al. [56] has also stated income, education and other social factors influences on farmers' adaptation decision.

Both access to extension service and gender of household head were also significant to adoption of control measure at $10 \%$ level of significance. Chances of adoption of prevention measures are 3.5 times more if the household head is male and 6.2 times more if household head has access to extension service. Male are supposed to take prompt decision and have access to resources in Nepalese society, thus chances of adoption also increases compare female household head. But this is inconsistent with finding of Nhemachena and Hassan [57], which reported female headed household are more likely to adopt. Genius et al. [58] also suggested extension services as strong determinants of technology adoption and diffusion.

\subsection{Vulnerability assessment of erosion}

The result showed that there is great variation in individual household vulnerability in the study area (Fig. 4). Erosion vulnerability varied from -7.33 (very high vulnerability) to 7.27 (least vulnerability). The village wise result (Table 9) showed Sindhukot is more vulnerable to erosion than Thakani. Result resembles with geography of Sindhukot as it possess more sloppy terrain than Thakani. On analyzing the vulnerability of the individual households, the result showed that household having low illiteracy ratio, low independent population, low male population proportion

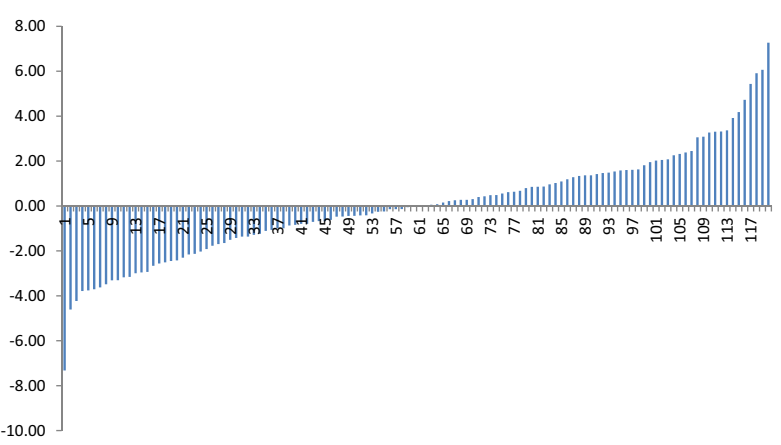

Fig. 4 Distribution of vulnerability index among households in the study area. Note: The most vulnerable household is placed at the extreme left and numbered one

Table 9 Vulnerability index by village

\begin{tabular}{lllll}
\hline Village & Adaptive capacity & Sensitivity & Exposure & $\begin{array}{l}\text { Vulner- } \\
\text { ability } \\
\text { index }\end{array}$ \\
\hline Thakani & 21.818 & -10.764 & 2.955 & 29.63 \\
Sindhukot & -21.552 & 10.764 & -2.955 & -29.36 \\
Overall & 0.268 & -0.000 & 0.000 & 0.268 \\
\hline
\end{tabular}


Table 10 Vulnerability index

\begin{tabular}{lll}
\hline Category & Range & $\begin{array}{l}\text { Number of } \\
\text { households }\end{array}$ \\
\hline Very high & $<-4.41$ & $5(4.17)$ \\
High & Low -1.49 to -4.41 & $24(20)$ \\
Medium & 1.43 to -1.49 & $62(51.67)$ \\
Low & $4.35-1.43$ & $27(22.5)$ \\
Very low & $>4.35$ & $2(1.67)$ \\
Total & & $120(100)$ \\
\hline
\end{tabular}

Note: Values in parentheses denote percentage

and low education of household head are more vulnerable to erosion than household having higher value of these variables. People depended on rain fed subsistence agriculture, own little land or other physical assets and have low education are more vulnerable to climate change [59]. Involvement in social group and access to extension also helps to reduce vulnerability. These socioeconomic factors highly influence the vulnerability. Similarly households having more per capita income are less vulnerable and vice versa. The greater the household's level of assets, more the capacity to cope with risk and the lower its level of vulnerability [60].

The observations are divided into quintiles to categorize the vulnerability of the farmers. The categories are very high, high, medium, low and very low. Most of the household falls under medium vulnerability to soil erosion whereas least households are very low vulnerable to erosion (Table 10).

\section{Conclusion}

Perception based study was carried out through semi structured questionnaire household survey and secondary data from different governmental and nongovernmental sources. Among different disasters, erosion and landslides are the most recurrent in Sindhukhola sub-watershed region. Various descriptive and inferential statistics were performed based on the household survey data. Maize was the important crop of farming system practiced in the surveyed area. Demographic information of the respondents showed most of the household depends on agriculture for their livelihood. Intensity of erosion was increasing moderately as per farmers' response which was in par with various findings but there was not significant effect on maize yield. Various prevention measures like shifting cultivation time, improved drainage system, reduced weeding frequency, minimum tillage and mulching were practiced by farmers. But most of the farmers were not adopting erosion prevention measures due to no government support, low income, no credit facility and poor access to technology. Logit regression analysis was performed to assess the determinants of adoption decision of prevention measures. Household income, gender and education of household head, access to extension services and involvement in social organization was found significant among various independent variables. Erosion prevention measures require expenses thus with increasing income level of adoption also increases. Educated $\mathrm{HH}$ head may go for innovative decision. Involvement in organization and access to extension services may help to develop knowledge on prevention measures. The study revealed most of the farmers are moderately vulnerable to soil erosion. Farmers living below poverty line, dependent on rain-fed farming and holding low asset are more vulnerable to erosion as these people have low adaptive capacity. Households with low literacy rate, higher dependent population proportion, higher female population proportion and higher agriculture income proportion are more vulnerable to erosion.

Our findings suggest that government must introduce safety nets like subsidy in use of prevention measures to vulnerable people living in erosion prone area. Different mitigation measure needs to be made easily available to the farmers, so they can adopt and minimize the chances of loss that may occur due to erosion. In high erosion prone area, government must use engineering techniques like construction of wall, check dam, etc. Conservation tillage must be encouraged in sloppy terrain. Construction of waterways along slope in maize field will reduce damage to soil. Cover crop, mulching, strip planting and contour farming will reduce runoff and increase water infiltration. Adjustment to climatic change and selection of resistant variety will also minimize the possible damage in yield. Government also needs to invest on social assets to minimize the vulnerability of disaster.

Acknowledgements This study was supported by United Nation Development Program (UNDP), Nepal. The authors sincerely thank Hari Krishna Panta, Huma Neupane and Santosh Pathak for their insights and help at various stages of research. Authors are very thankful to all the residents of the study area who shared their indigenous knowledge with us, and extend sincere gratitude to the anonymous reviewers for their valuable time.

\section{Compliance with ethical standard}

Conflict of interest This manuscript describes original work and is not under consideration by any other journal. All authors approved the manuscript and this submission. The authors declare no conflict of interest. 


\section{References}

1. MoHA (2015) National strategy for disaster risk management. Retrieved on 2019 from http://www.nrcs.org/sites/default/ files/pro-doc/NSDRM\%20Nepal.pdf

2. Dangal R (2011) Country profile Nepal. Disaster risk management: policies and practices in Nepal. Asian Disaster Reduction Center, Kobe

3. NSET (2008) National strategy for disaster risk management in Nepal. Retrieved on 2019 from http://www.nrcs.org/sites/ default/files/pro-doc/NSDRM\%20Nepal.pdf

4. Nyssen J, Poesen J, Deckers J (2009) Land degradation and soil and water conservation in tropical highlands. Soil Tillage Res 103(2):197-202

5. Fort M, Cossart E, Arnaud-Fassetta G (2010) Hillslope-channel coupling in the Nepal Himalayas and threat to man-made structures: the middle Kali Gandaki valley. Geomorphology 124(3-4):178-199

6. Ghimire SK, Higaki D, Bhattarai TP (2013) Estimation of soil erosion rates and eroded sediment in a degraded catchment of the Siwalik Hills, Nepal. Land 2(3):370-391

7. Paudel B, Zhang Y, Yan J, Rai R, Li L, Wu X, Chapagain PS, Khanal NR (2020) Farmers' understanding of climate change in Nepal Himalayas: important determinants and implications for developing adaptation strategies. Clim Chang 158:485502. https://doi.org/10.1007/s10584-019-02607-2

8. Shrestha DP (1997) Assessment of soil erosion in the Nepalese Himalaya: a case study in Likhu Khola Valley, Middle Mountain Region. Land Husbandry 2(1):59-80

9. MFSC (2006) Sacred Himalayan landscape-Nepal strategic plan (2006-2016) broad strategy document. His Majesty's Government of Nepal, Ministry of Forests and Soil Conservation, Kathmandu

10. Atreya K, Sharma S, Bajracharya RM, Rajbhandari NP (2006) Applications of reduced tillage in hills of central Nepal. Soil Tillage Res 88(1-2):16-29

11. Raut N, Sitaula BK, Bajracharya RM (2010) Agricultural intensification: linking with livelihood improvement and environmental degradation in mid-hills of Nepal. J Agric Environ 11:83-94

12. Morgan RPC, Morgan DDV, Finney HJ (1984) A predictive model for the assessment of soil erosion risk. J Agric Eng Res 30:245-253

13. CBS (2018) Statistical pocket book Nepal 2018. Government of Nepal, National Planning Commission Secretariat, Central Bureau of Statistics, Kathmandu

14. Paudyal KR (2001) Maize in Nepal: production systems, constraints, and priorities for research. CIMMYT, Kathmandu

15. Acharya TD, Yang IT (2015) Landslide hazard zonation using GIS: a case study from Sindhupalchowk, Nepal. Int J Appl Eng Res (IJAER) 10(7):18385-18394

16. Poudyal CP (2013) Hazard mapping of Sindhu khola watershed, Sindhupalchowk, Nepal. Kathmandu Univ J Sci Eng Technol 9:68-82

17. Dahal RK (2012) Rainfall-induced landslides in Nepal. Int J Eros Control Eng 5(1):1-8

18. Cutter SL, Emrich CT, Webb JJ, Morath D (2009) Social vulnerability to climate variability hazards: a review of the literature. Final report to Oxfam America. Hazards and Vulnerability Research Institute, University of South Carolina, Columbia

19. Sharma TPP, Zhang J, Koju UA, Zhang S, Bai Y, Suwal MK (2019) Review of flood disaster studies in Nepal: a remote sensing perspective. Int J Disaster Risk Reduct 34:18-27

20. Boruff BJ, Emrich C, Cutter SL (2005) Erosion hazard vulnerability of US coastal counties. J Coast Res 215:932-942
21. Holand IS, Lujala P, Rød JK (2011) Social vulnerability assessment for Norway: a quantitative approach. Norsk Geografisk Tidsskrift-Norwegian J Geogr 65(1):1-17. https://doi. org/10.1080/00291951.2010.550167

22. IPCC (2007) Climate change 2007 synthesis report. In: Core Writing Team, Pachauri RK, Reisinger A (eds) Contribution of working groups I, II and III to the fourth assessment report of the Intergovernmental Panel on Climate Change. IPCC, Geneva

23. Nicholas $\mathrm{O}$, Madukwe MC, Enete AA, Amaechina EC, Onokala $P$, Eboh EC, Ujah O, Garforth CJ (2012) A framework for agricultural adaptation to climate change in Southern Nigeria. Int J Agric Sci 4(5):243-251

24. CBS (2019) District profile Sindhupalchowk 2075BS. Government of Nepal, National Planning Commission Secretariat, Central Bureau of Statistics, Kavreplanchowk

25. Karki R, Talchabhadel R, Aalto J, Baidya SK (2016) New climatic classification of Nepal. Theor Appl Climatol 125(3-4):799-808

26. Uddin K, Shrestha HL, Murthy MSR, Bajracharya B, Shrestha B, Gilani H, Dangol B (2015) Development of 2010 national land cover database for the Nepal. J Environ Manag 148:82-90

27. Gujarati D (2003) Basic econometrics. McGraw Hill Publication, Boston, MA

28. National Economic Census (2018) Analytical report no. 2 Comparative analysis by industry. Government of Nepal, National Planning Commission Central Bureau of Statistics, Kathmandu, p 2020

29. Miah AQ (1993) Applied statistics: a course handbook for human settlements planning. Asian Institute of Technology, Division of Human Settlements Development, Bangkok, pp 316-318

30. IPCC (2014) Climate change 2014: synthesis report. Contribution of working groups I, II and III to the fifth assessment report of the Intergovernmental Panel on Climate Change. IPCC, Geneva

31. Sitaula BK, Žurovec O, Luitel BC, Parker A, Lal R (2020) Need for personal transformations in a changing climate: reflections on environmental change and climate-smart agriculture in Africa. In: Climate impacts on agricultural and natural resource sustainability in Africa. Springer, Cham, pp 347-370

32. Balica SF, Wright NG, Van der Meulen F (2012) A flood vulnerability index for coastal cities and its use in assessing climate change impacts. Nat Hazards 64(1):73-105

33. Vincent K (2004) Creating an index of social vulnerability to climate change for Africa. Tyndall Center for Climate Change Research. Working Paper, vol 56(41), pp 1-50

34. Tran LT, O'Neill RV, Smith ER (2010) Spatial pattern of environmental vulnerability in the Mid-Atlantic region, USA. Appl Geogr 30(2):191-202

35. Deressa TT, Hassan RM, Ringler C, Alemu T, Yesuf M (2009) Determinants of farmers' choice of adaptation methods to climate change in the Nile Basin of Ethiopia. Glob Environ Chang 19(2):248-255

36. Pathak S, Panta HK, Bhandari T, Paudel KP (2020) Flood vulnerability and its influencing factors. Nat Hazards. https://doi. org/10.1007/s11069-020-04267-3

37. Chalise D, Kumar L (2018) Land use change impacts on soil erosion dynamics in western Nepal. University of New England, Armidale

38. Uddin K, Abdul Matin M, Maharjan S (2018) Assessment of land cover change and its impact on changes in soil erosion risk in Nepal. Sustainability 10(12):4715

39. Gabet EJ, Burbank DW, Pratt-Sitaula B, Putkonen J, Bookhagen B (2008) Modern erosion rates in the High Himalayas of Nepal. Earth Planet Sci Lett 267(3-4):482-494

40. Talchabhadel R, Prajapati R, Aryal A, Maharjan M (2020) Assessment of rainfall erosivity (R-factor) during 1986-2015 across Nepal: a step towards soil loss estimation. Environ Monit Assess 192:1-17 
41. Shen $H$, Zheng F, Wen $L$, Han $Y$, Hu W (2016) Impacts of rainfall intensity and slope gradient on rill erosion processes at loessial hillslope. Soil Tillage Res 155:429-436

42. West AJ, Arnold M, Aumal̂tre G, Bourlès DL, Keddadouche K, Bickle M, Ojha T (2015) High natural erosion rates are the backdrop for present-day soil erosion in the agricultural Middle Hills of Nepal. Earth Surf Dyn 3(3):363

43. Osbahr H, Twyman C, Adger WN, Thomas DSG (2008) Effective livelihood adaptation to climate change disturbance: scale dimensions of practice in Mozambique. Geoforum 39(6):1951-1964

44. Das R, Bauer S (2012) Bio-economic analysis of soil conservation technologies in the mid-hill region of Nepal. Soil Tillage Res 121:38-48

45. Paudel B, Radovich TJ, Chan-Halbrendt C, Crow S, Tamang BB, Halbrendt J, Thapa K (2014) Effect of conservation agriculture on maize-based farming system in the mid-hills of Nepal. Proc Eng 78:327-336

46. Atreya K (2002) Management effects on soil and nutrient losses and crop productivity in maize-based cropping systems of the central Nepal mid-hills. Doctoral dissertation, MSc Thesis, Department of Biological and Environmental Sciences, Kathmandu University, Nepal

47. Kunwar LB, Bergsma E, Shrestha DP (2003) Rain erosion hazard evaluated from microtopographic erosion features on arable fields and forest: a case study in Nepal. Geogr Ann Ser A Phys Geogr 85(3-4):313-321

48. Gardner RAM, Gerrard AJ (2003) Runoff and soil erosion on cultivated rainfed terraces in the Middle Hills of Nepal. Appl Geogr 23(1):23-45

49. Brouwer R, Akter S, Brander L, Haque E (2007) Socioeconomic vulnerability and adaptation to environmental risk: a case study of climate change and flooding in Bangladesh. Risk Anal 27(2):313-326. https://doi.org/10.1111/j.1539-6924.2007.00884.

50. Ishaya S, Abaje IB (2008) Indigenous people's perception on climate change and adaptation strategies in Jema'a local government area of Kaduna State, Nigeria. J Geogr Regional Plan 1(8): 138

51. Daba S (2003) An investigation of the physical and socioeconomic determinants of soil erosion in the Hararghe Highlands, eastern Ethiopia. Land Degrad Dev 14(1):69-81. https://doi. org/10.1002/ldr.520
52. Daberkow SG, McBride WD (2003) Farm and operator characteristics affecting the awareness and adoption of precision agriculture technologies in the U.S. Prec Agric 4:163-177

53. Okoye C (1998) Comparative analysis of factors in the adoption of traditional and recommended soil erosion control practices in Nigeria. Soil Tillage Res 45(3-4):251-263. https://doi. org/10.1016/s0933-3630(96)00137-7

54. Nadhomi D, Tenywa J, Musali P, Nakileza B (2013) Farmers' perception of erosion risk and its implication on the adoption of soil and water conservation practices. Int J Adv Agric Sci Technol 2(1):28-44. http://scientific.cloud-journals.com/index.php/IJAAS T/article/view/Sci-122

55. Tiwari KR, Sitaula BK, Nyborg IL, Paudel GS (2008) Determinants of farmers' adoption of improved soil conservation technology in a middle mountain watershed of central Nepal. Environ Manag 42(2):210-222. https://doi.org/10.1007/s0026 7-008-9137-z

56. Jianjun J, Yiwei G, Xiaomin W, Nam PK (2015) Farmers' risk preferences and their climate change adaptation strategies in the Yongqiao District, China. Land Use Policy 47:365-372. https:// doi.org/10.1016/j.landusepol.2015.04.028

57. Nhemachena C, Hassan R (2007) Micro-level analysis of farmers adaption to climate change in Southern Africa. International Food Policy Research Institute, Washington, DC

58. Genius M, Koundouri P, Nauges C, Tzouvelekas V (2014) Information transmission in irrigation technology adoption and diffusion: social learning, extension services, and spatial effects. Am J Agric Econ 96(1):328-344

59. Gentle P, Maraseni TN (2012) Climate change, poverty and livelihoods: adaptation practices by rural mountain communities in Nepal. Environ Sci Pol 21:24-34. https://doi.org/10.1016/j.envsc i.2012.03.007

60. Vatsa KS (2004) Risk, vulnerability and asset-based approach to disaster risk management. Int J Sociol Soc Policy 24(10/11):1-48

Publisher's Note Springer Nature remains neutral with regard to jurisdictional claims in published maps and institutional affiliations. 